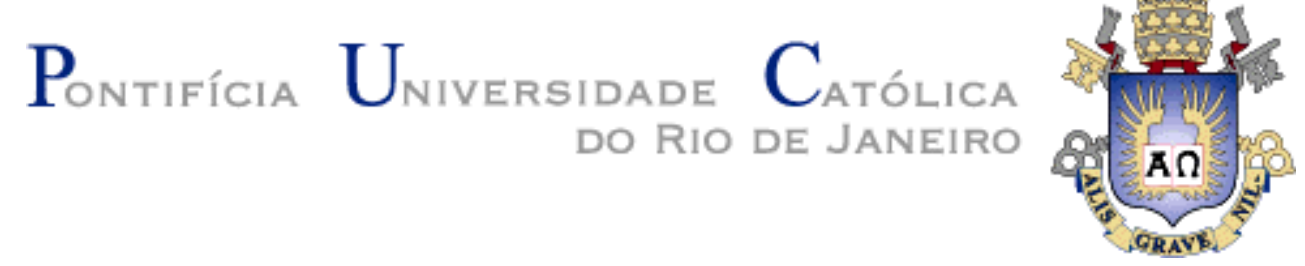

Guilherme Schirmer de Souza

Renderização de Pele Humana em Tempo Real para Jogos

Dissertação de Mestrado

Dissertação apresentada como requisito parcial para obtenção do título de Mestre pelo Programa de Pós-Graduação em Informática da PUC-Rio.

Orientador: Prof. Bruno Feijó 
Guilherme Schirmer de Souza

\title{
Renderização de Pele Humana em Tempo Real para Jogos
}

\begin{abstract}
Dissertação apresentada como requisito parcial para obtenção do título de Mestre pelo Programa de PósGraduação em Informática da PUC-Rio. Aprovada pela Comissão Examinadora abaixo assinada.
\end{abstract}

Prof. Bruno Feijó Orientador Departamento de Informática - PUC- Rio

Prof. Cesar Tadeu Pozzer Departamento de Eletrônica e Computação - UFSM

Prof. Alberto Barbosa Raposo Departamento de Informática - PUC- Rio

Prof. José Eugenio Leal Coordenador(a) Setorial do Centro Técnico Científico - PUC-Rio 
Todos os direitos reservados. É proibida a reprodução total ou parcial do trabalho sem autorização da universidade, do autor e do orientador.

\section{Guilherme Schirmer de Souza}

Graduou-se em Engenharia da Computação no IME (Instituto Militar de Engenharia) em 2006. Ingressou no programa de mestrado do Departamento de Informática em 2008. Desde 2009, ajuda o VisionLab na construção do motor de jogos, Mob3D. Atualmente trabalha na indústria privada na área de desenvolvimento de softwares.

Ficha Catalográfica

Souza, Guilherme Schirmer de
Renderização de pele humana em tempo real
para jogos / Guilherme Schirmer de Souza ; orientador:
Bruno Feijó. - 2010.
101 f. : il.(color.) ; $30 \mathrm{~cm}$
Dissertação (mestrado)-Pontifícia Universidade
Católica do Rio de Janeiro, Departamento de Informática,
2010.
Inclui bibliografia
1. Informática - Teses. 2. Pele humana. 3. Perfil
de difusão. 4. Espalhamento e absorção da luz. 5. Espaço
da textura. I. Feijó, Bruno. II. Pontifícia Universidade
Católica do Rio de Janeiro. Departamento de Informática.
III. Título.

CDD: 004 


\section{Agradecimentos}

Primeiramente, agradeço à minha namorada Alessandra por todo o amor que me passa e por me incentivar, suportar e me equilibrar em todos os momentos nesse período da minha vida.

À minha família, por todo o amor, carinho e apoio transmitidos a vida inteira, sem os quais não chegaria onde estou.

Ao meu orientador, por todo o conhecimento, incentivo e apoio durante todo esse tempo.

Aos professores do departamento, por todo o conhecimento passado.

Ao departamento, à PUC-Rio e ao CAPES, por ter me dado a oportunidade de estudar nessa universidade e pelo apoio financeiro.

E finalmente, agradeço à empresa XYZRGB, por fornecer as texturas de alta definição e o modelo tridimensional utilizados na realização do desenvolvimento e testes dessa dissertação. 


\section{Resumo}

Souza, Guilherme Schirmer de; Feijó, Bruno. Renderização de Pele Humana em Tempo Real para Jogos. Rio de Janeiro, 2010. 101p. Dissertação de Mestrado - Departamento de Informática, Pontifícia Universidade Católica do Rio de Janeiro.

A renderização de pele humana é um tópico de pesquisa fundamental para a indústria de entretenimento digital. Obter resultados realistas é bastante desafiador, ainda mais quando o objetivo do uso se destina a aplicações em tempo real. Nessa dissertação são estudadas e implementadas duas técnicas para simular o comportamento da luz através da pele humana. Ambas são baseadas em modelos físicos e empíricos e utilizam o espaço da textura na GPU para reproduzir a iluminação difusa e espalhamento transluminoso (subsurface scattering) em tempo real. Essa dissertação compara estas duas técnicas e dá orientações para a implementação de um módulo de renderização de pele humana em motores de jogos 3D.

\section{Palavras-chave}

pele humana; perfil de difusão; espalhamento e absorção da luz; espaço da textura 


\section{Abstract}

Souza, Guilherme Schirmer de; Feijó, Bruno (Advisor). Real Time Skin Rendering for Games. Rio de Janeiro, 2010. 101p. Msc, Dissertation Departamento de Informática, Pontifícia Universidade Católica do Rio de Janeiro.

Skin rendering is a fundamental research topic for the digital entertainment industry. Realistic results are very challenge to obtain, especially for real time applications. In this dissertation, two skin rendering techniques are studied and developed to simulate light behavior through human skin. Both techniques are based on physic and empiric models and use texture space in GPU to reproduce diffuse illumination and subsurface scattering in real time. This dissertation compares these two techniques and gives guidelines for the implementation of a skin rendering module in 3D game engines.

\section{Keywords}

skin rendering; diffusion profiles; subsurface scattering in skin; texture diffusion. 


\section{Sumário}

1 Introdução

2 Trabalhos Relacionados

3 Comportamento da Luz na Pele Humana

4 Técnicas de Renderização da Pele Humana

4.1. Técnica da Convolução de Poisson (Gosselin et al. 2004a) 24

4.1.1. Mapa de Sombra 26

4.1.2. Iluminação Difusa (Mapa de Irradiância ou Light Map) 30

4.1.3. O Processo de Convolução de Poisson (Blurs) 31

4.1.4. Reflexão Especular 34

4.1.5. Renderização Final da Malha 35

4.2. Técnica dos Perfis de Difusão (d’Eon e Luebke 2007) 37

4.2.1. Perfis de Difusão 39

4.2.2. Iluminação Difusa (Mapa de Irradiância) 42

4.2.3. Convoluções da Textura de Irradiância 42

4.2.4. Correção da Distorção do Unwrap 47

4.2.5. Simulação de Não-Uniformidades da Pele 49

4.2.6. Conservação de Energia 51

4.2.7. Mapa de Sombra Translúcido Modificado e o Espalhamento Global da Luz $\quad 53$

4.2.8. Renderização Final da Malha $\quad 56$

5 Implementação $\quad 59$

5.1. Visão Geral do Mob3D 59

5.2. Ambiente de Desenvolvimento e Arquitetura da Solução 60

5.2.1. Organização da Solução 61

5.2.2. Shaders 62

5.2.3. Entradas e Saídas $\quad 69$ 
5.3. Detalhes de Implementação

5.3.1. Otimizações

6 Resultados

6.1. Análise de Desempenho 85

6.2. Análise de Qualidade 88

6.3. Visão Geral 93

7 Conclusão 95

$\begin{array}{ll}\text { Referências Bibliográficas } & 99\end{array}$ 


\section{Lista de figuras}

Figura 1 - Na imagem da esquerda (a), a renderização da pele foi realizada sem considerar o espalhamento e absorção interna da luz. Nota-se que a pele fica seca e com uma aparência não natural. A imagem da direita (b) considera o subsurface scattering, criando assim uma pele com traços mais suaves e naturais.

Figura 2 - A imagem mostra a luz incidente chegando à camada mais externa da pele e sendo refletida em diversos ângulos. A parte não refletida está omitida.

Figura 3 - Espalhamento da luz através das camadas internas da pele. Um único raio de luz pode entrar em um ponto e sair por vários.

Figura 4 - Algoritmo de iluminação da pele humana de Gosselin et al. (2004a): inicialmente é gerado o mapa de sombra com base na malha 3D, após isso, é criada a textura de irradiância, onde o cálculo difuso de iluminação é feito considerando as sombras. Posteriormente, vários blurs são realizados na textura de irradiância, criando assim uma textura final a ser utilizada na malha. Além disso, na última parte, é realizado o cálculo de iluminação especular, para gerar o resultado final.

Figura 5 - A imagem à esquerda (a) representa a cena sendo renderizada tendo como ponto de vista a fonte de luz. No mapa de sombra (linha vermelha) é armazenada a distância de cada ponto do objeto sendo iluminado. $\mathrm{Na}$ imagem à direita (b), a cena é renderizada tendo o observador como ponto de vista. O ponto $B$ visto pelo observador é iluminado, pois a distância do ponto à fonte de luz é igual (ou muito próxima) da distância armazenada no mapa de sombra. Já o ponto $A$ está em sombra, pois a distância desse ponto à fonte de luz é bem maior do que a distância armazenada no mapa de sombra.

Figura 6 - Exemplo de mapa de sombra de uma malha iluminada por um ponto de luz. Nesse mapa é armazenada a distância de cada ponto para a luz. 
Figura 7 - A imagem à esquerda (a) mostra o resultado da aplicação do uso da técnica do Shadow Map. Pode ser visto que uma sombra forte é criada. A imagem à direita mostra o resultado da sombra gerada após os blurs da textura de irradiância. Nota-se que a sombra fica mais suave e o resultado mais parecido com a realidade.

Figura 8 - Exemplo de mapa de irradiância com sombras.

Figura 9 - Exemplo de textura gerada após algumas convoluções de Poisson realizadas na textura de irradiância.

Figura 10 - Exemplo de reflexão especular com o uso da técnica de Kelemen/Szirmay-Kalos (2001). Nessa imagem o contraste foi alterado para facilitar a visualização.

Figura 11 - Exemplo de pele humana gerada com o algoritmo de Gosselin et al. (2004a). A imagem apresenta o resultado da junção das componentes difusa e especular.

Figura 12 - Visão geral do algoritmo de d'Eon e Luebke (2007) para renderização de pele humana.

Figura 13 - Um feixe de luz ao entrar em uma superfície espalha-se ao redor do ponto de entrada, iluminando as regiões (radialmente) ao redor desse ponto.

Figura 14 - Exemplo das regiões afetadas pelo espalhamento das cores azul, verde e vermelha ao redor de um ponto em um determinado material. Figura 15 - Exemplo de resultado obtido pela primeira convolução (representando a segunda gaussiana) da textura de irradiância.

Figura 16 - Exemplo de resultado obtido após todas as convoluções (representando a sexta gaussiana) da textura de irradiância.

Figura 17 - Exemplo de Stretch Texture. Essa textura é uma imagem RGB onde na primeira coordenada é armazenada a correção na direção $x$ e na segunda, a correção na direção $y$, conforme a equação (27).

Figura 18 - Aplicando certo padrão ao modelo utilizado, pode-se perceber o problema ocasionado devido a não correção da distorção causada pelo unwrap da malha. A imagem à esquerda (a) não possui correção alguma durante o processo de blur da textura de irradiância. Pode-se perceber que a orelha foi largamente afetada e "manchada". Já na imagem à direita (b), a 
distorção foi ajustada de acordo com a região da face, amenizando assim borrões indevidos.

Figura 19 - A figura à esquerda (a) mostra um exemplo de coloração antes do blur do mapa de irradiância, enquanto que a figura à direita mostra um exemplo de coloração feita após as convoluções. A figura à esquerda apresenta uma pele com cor mais suavizada, porém perde detalhes da camada mais superficial da pele, como a barba, exibidos na figura à direita.

Figura 20 - Exemplo de resultado obtido utilizando um mix entre coloração antes e depois do blur da textura de irradiância.

Figura 21 - Esquema do modelo matemático do espalhamento da luz pela pele até o ponto $C$.

Figura 22 - Exemplo de TSM modificado. Assim como o Shadow Map, armazena a distância dos pontos iluminados até a luz na coordenada R. Nas coordenadas G e B, são armazenadas as coordenadas de textura $U$ e $V$ desses pontos.

Figura 23 - Exemplo de espalhamento global da luz. A parte de trás da orelha não sofre iluminação direta, porém devido ao subsurface scattering da pele, uma parte da luz chega e a ilumina.

Figura 24 - Exemplo de resultado obtido utilizando a técnica de renderização de pele humana apresentada por d'Eon e Luebke (2007).

Figura 25 - Arquitetura geral do Mob3D e o contexto do Módulo de Geração de Pele Humana.

Figura 26 - Organização dos arquivos, de acordo com suas funções, fora do RenderMonkey e com os trechos de código mais importantes.

Figura 27 - Organização do módulo de geração de pele humana com vários passos.

Figura 28 - Entradas e saídas do algoritmo de Gosselin et al. (2004a). A malha tridimensional com suas texturas de alta definição para a cor, normal e kernel size (ver seção 5.3) é introduzida no módulo de renderização de pele humana o qual processa os dados de entrada em conjunto com uma série de variáveis para reproduzir a pele humana. As variáveis globais envolvem cor da luz, posição da luz, tolerância de erro de 
distância no Shadow Map, entre outras. Já as variáveis locais englobam basicamente matrizes de conversão de base.

Figura 29 - Entradas e saídas do algoritmo de d'Eon e Luebke (2007). A malha tridimensional com suas texturas de alta definição para a cor e normal é introduzida no módulo de renderização de pele humana o qual processa os dados de entrada em conjunto com várias variáveis para reproduzir a pele humana. Além disso, são passadas as texturas adicionais Stretch Map e de atenuação de energia (ver seção 5.3). As variáveis globais envolvem cor da luz, posição da luz, tolerância de erro de distância no Shadow Map, pesos das gaussianas, desvio padrão das gaussianas, entre outras. Já as variáveis locais englobam basicamente matrizes de conversão de base.

Figura 30 - Convoluções nas regiões de borda, como, por exemplo, a região selecionada na imagem, podem fazer com que as cores de background se misturem com as cores do objeto.

Figura 31 - Aparição de artefatos indesejados devido ao unwrap da malha e as convoluções da textura de irradiância.

Figura 32 - Todo objeto se encontra dentro do frustum de visão da câmera.

Figura 33 - O objeto não se encontra totalmente na região de visão da câmera, logo não deve ser realizado todo o processamento no espaço da textura. As partes em azul à direita (b) são cortadas pelo hardware, pois seu processamento é desnecessário. Com isso o algoritmo fica mais rápido. Figura 34 - Em azul na figura à direita (b) está o corte realizado pelo hardware dos pixels desnecessários. Nota-se que a parte ignorada é grande, o que aumenta o desempenho do algoritmo.

Figura 35 - Na imagem à esquerda (a) está o mapa de cor original. Pode-se perceber que as regiões em preto não fazem parte do objeto e podem ser ignoradas no processamento. $\mathrm{Na}$ imagem à direita aparece em azul toda a região na qual o processamento dos pixels foi desconsiderado.

Figura 36 - Ângulo de visão considerado por todos os cenários para capturar o framerate.

Figura 37 - Visão frontal dos dois algoritmos. A sombra no olho esquerdo do objeto está mais suave na imagem (b), porém detalhes dos poros na 
testa são perdidos na mesma. Além disso, a barba se encontra mais suave na imagem (a), pois a aplicação da cor do mapa de cor é aplicada antes e depois dos blurs (seção 4.2.5).

Figura 38 - Visão lateral dos modelos. Assim como na Figura 37, as sombras estão mais suaves com o algoritmo de Gosselin et al. (2004a). Em compensação, pode-se perceber na imagem (b) que vários detalhes na bochecha, na orelha e na junta entre orelha e cabeça são perdidos.

Figura 39 - Visão traseira das técnicas. Pode-se perceber que a imagem à esquerda (a) apresenta muito mais detalhes da pele, além de apresentar o espalhamento global da luz na orelha. Também é visualizada a reflexão especular nos modelos (embora ambas as técnicas utilizem o mesmo modelo especular, a diferença nesse aspecto se dá devido à forma final como o termo é calculado, conforme as equações (18) e (35)). Figura 40 - Visão traseira dos modelos. Nessa situação as técnicas não apresentam muitas diferenças entre si. Pode-se perceber que os artefatos indesejados devido ao unwrap (seção 5.3) são corrigidos perfeitamente. Figura 41 - Visão frontal dos modelos. Assim como na Figura 39, nessa imagem é apresentado o espalhamento global da técnica de d'Eon e Luebke (2007) e as diferenças em nível de detalhes da pele e reflexão especular de ambas as técnicas. 


\section{Lista de tabelas}

Tabela 1 - Conjuntos de contribuições para a renderização de pele humana em tempo real. São consideradas contribuições diretas os trabalhos derivados da técnica de iluminação difusa da pele através do uso do espaço da textura.

Tabela 2 - Parâmetros das seis gaussianas que formam o perfil de difusão para as cores vermelha, verde e azul de um homem caucasiano (d'Eon e Luebke 2007).

Tabela 3 - A tabela mostra todos os passos para realização da técnica de Gosselin et al. (2004a). Além disso, é exibido em que passo e em qual shader cada etapa da técnica deve ser aplicada.

Tabela 4 - A tabela mostra os passos para realização da técnica de d'Eon e Luebke (2007). Além disso, é exibido em que passo e em qual shader cada etapa da técnica descrita na seção 4.2 deve ser aplicada.

Tabela 5 - Entradas e saídas de cada passo do algoritmo de Gosselin et al. (2004a).

Tabela 6 - Entradas e saídas de cada passo do algoritmo de d'Eon e Luebke (2007).

Tabela 7 - Resumo geral das condições para corrigir artefatos gerados nas bordas dos objetos devido ao unwrap da malha.

Tabela 8 - Quadro comparativo com os frames por segundo aproximados para cada uma das máquinas e dos cenários analisados. 